\title{
A Model to Assess Technological Innovations at Institutions of Higher Learning in Kenya
}

\author{
Article by Rajab Philip Muchiri \\ Computer Science, Texila American University, Kenya \\ E-mail: philipmuchiri2014@gmail.com
}

\begin{abstract}
Objective: The aim was to develop an innovation assessment model to analyse the impact of broadband in spurring innovations in Kenya by studying the role of broadband diffusion, the impact of broadband collaborations, the influence of electronic research and the role of online broadband products usability.

Background: Many countries in Africa invest in broadband infrastructure because they have realized that broadband encourages innovation leading to economic development and prosperity. Understanding the relationship between universities, business enterprises and government enabled by broadband is critical in assessing a country's innovative capacity.

Methodology: This study applied descriptive survey research design. It used a logistic regression model as an inferential analysis tool in the quantitative aspects of the research. The target population for this study was institutions of higher learning (IHL) operating in Kenya by 31st December, 2015 which included both private and public accredited universities in Kenya.

Results: The response rate from the sampled population was at $75 \%$ Reliability measures were above the recommended level of 0.70 as an indicator for adequate internal consistency. The overall model evaluation, goodness-of-fit statistics, statistical tests of individual predictors and validations of predicted probabilities. Showed that the data fitted the model and the model performed well.

Conclusion: Institutions of higher learning in Kenya have a positive but low capacity in technological innovation implementation. Broadband diffusion is inhibited by poor infrastructural development attributed to high costs of connections and bandwidth acquisition and a high demand for broadband among the students and staff.
\end{abstract}

Keywords: Broadband, Innovation, Internet, Education, model.

\section{Introduction}

The role of broadband (BB) technology in Institutions of Higher Learning (IHL) cannot be underestimated. Jhurree (2005) asserted that technology has the potential to drive educational, political and social transformations and advised that developing countries cannot ignore technology if they are to remain competitive in globalization era. Technology has become a non-negotiable aspect of students' lives and is a major attractor to students and the corporate sector in joining different IHL (The Economist Intelligence Unit (2008)). Research indicates that though there is a degree of application of technology in teaching and learning, this application is not commensurate to technology use in administration and social circles.

McGregor (2002) and Dodds (2007) viewed technology as a powerful contributor to strengthening IHL. Dodds (2007) believed technology had emancipator power that is able to assist institutions to move from the status quo and perform their functions in a much improved way. He categorized ICT's role as a contributor to innovation into three broad areas namely, building communities of innovation, changing institutional processes and implementing infrastructure and tools that enable people to succeed. ICT could create new possibilities for collaboration, remove barriers to effectiveness, assist in establishing continual communication and help build trust among people. While technology cannot be taken as a panacea for all educational challenges, "it does leverage and extend traditional teaching and learning activities in certain circumstances and hence has the potential to impact on learning outcomes" (Jaffer, Ng'ambi, \& Czerniewicz, 2007). 
The massive investment by IHL in broadband technology is evidence that institutions are cognizant of technology's potential in revolutionizing their operations (Jhurree, 2005). This indicates the readiness on the part of IHL management to make the most of potential benefits attributed to technology integration in their functional areas. Several studies presented evidence that despite significant investment and claimed benefits, the impact of BB technology on education has often been disappointing (Dawson, et al., 2012). Although most technological innovations are now emerging from developing countries, the massive spending in ICT with little to show for these investments, gives rise to a 'technology complex'. In fact Bertrand (2010) refers to this technological innovation transfer as the effect of "Technosclerosis" and contended that modern universities have fallen behind the pace of technological change and have become irrelevant in the real life of an interconnected and globalizing world.

Oliver (2002) supports Bertrand by claiming that the impact of technological innovations in IHL has not been as extensive as in other fields. He argued that there is a lack of congruence between the belief in technology's potential and the actual realization of the benefits that should accrue from adopting these innovations. It can be stated that IHL often invest in technology with alacrity but having limited understanding of how to manage the implementation process. Though there is much literature on technology adoption, the understanding of what leads to effective implementation and assessment once technology has been adopted remains blurred (Dong, et al., 2008). There is also limited information and understanding of the determinants and criteria applicable in assessing effective implementation of technological innovations in IHL. Literature is replete with information on key barriers to the successful implementations of BB innovations in IHL (Bertrand, et al., 2010).

Bertrand (2010) called for critical examination of factors related to education and administration that make institutions unable to be innovative. Unfortunately, failure to achieve effective implementation of innovations has negative consequences. They include; loss of the finances already sunk into the project, loss of the potential benefit of technology integration, opportunity costs relating to other resources that were sunk into the project, tarnished credibility of the management involved and the likelihood that management will in future be skeptical regarding use of broadband for innovation (Sawang \& Unsworth, 2007; Osei-Bryson, Dong, et al., 2008). The reason that most technology project implementations are ineffective and that institutions fail to reap the benefits of BB usability for innovative purposes is ineffective implementation arising from lack of knowledge rather than failure of the innovation being adopted (Sawang \& Unsworth, 2011). IHL in Africa need to understand what determines effective implementation of BB technology for innovative purpose and the criteria applicable for assessing innovation in this institution. This represents the main knowledge gap in the current study. The study endeavoured to bridge the gap between the high costs of investment in BB technology and its effective application for innovation in IHL.

\section{Triple helix systems}

This study adopts the Triple Helix system model of innovation. The Triple Helix idea is that the potential for innovation and economic development in a knowledge society lies in a more prominent role for the university and in the hybridisation of elements from university, government and industry to generate new institutional and social formats for the production, application and transfer of knowledge. This vision encompasses not only the creative destruction that appears as a natural innovation dynamics (Schumpeter, 1942), but also the creative renewal that arises within each of the three institutional spheres of university, industry and government, as well as at their intersections. This enhanced role of the university in the Knowledge Society arises from several specific developments. The first is the recent addition of the university involvement in socio-economic development, then next to the traditional academic missions of teaching and research (Etzkowitz, 2003).

This is to a large extent the effect of strong government policy to strengthen the links between universities and the rest of society such as business, but also an effect of firms' tendency to use universities' research infrastructure for their R\&D objectives, indirectly transferring part of their costs to the state which provides a large part of university funding (Slaughter and Leslie, 1997). The network linkages with the other Triple Helix actors have enhanced the central presence of universities 
in the production of scientific research over time (Godin and Gingras, 2000) disproving former views that increasing diversification of production loci would diminish the role of universities in the knowledge production process (Gibbons et al. 1994). The second is the university's capacity to continuously provide students with new skills and entrepreneurial talent has become a major asset in the Knowledge Society. This makes students not only the new generations of professionals in various scientific disciplines, but they can also be trained and encouraged to become entrepreneurs and innovators contributing to economic growth and job creation.

Universities are also extending their capabilities of educating individuals to educating organizations through entrepreneurship and incubation programmes and new training modules at venues such as inter-disciplinary centres, incubators, academic spin-offs and science parks (Etzkowitz et al., 2012). The third is universities' capacity to generate technology has transformed its responsibility from a traditional source of human resources and knowledge to a new source of technology generation and transfer, increasing internal organizational capabilities to produce and formally transfer technologies rather than relying solely on informal ties. The Triple Helix literature body has been developed consisting the following two main complementary perspectives:

A (neo)institutional perspective (Etzkowitz et al., 2008) encompasses case studies and comparative historical analyses that explore different configurations arising from the positioning of the university, industry and government institutional spheres relative to each other and their movement and reorientation, with one as a gravitational centre around which the others rotate (Fig.2.3). Government may play the lead role for instance in a statist regime, driving academia and industry but also limit its capacity to initiate and develop innovative transformations (such as in Russia, China, some Latin American and Eastern Europe countries). Meanwhile in a laissez-faire regime, characterised by a limited state intervention in the economy (such as the US and some Western European countries), industry is the driving force with the other two spheres as ancillary support structures and limited roles in innovation.

The university here acts mainly as a provider of skilled human capital while government mainly as a regulator of social and economic mechanisms. A balanced regime is emerging in the transition to a Knowledge Society, whereby university and other knowledge institutions play increasing role acting in partnership with industry and government and even taking the lead in joint initiatives (Etzkowitz, 2008). The balanced model offers the most important insights, as the best environments for innovation are created at the intersections of the spheres. Here, creative synergies emerge and set in motion a process of "innovation in innovation", creating new venues for interaction and new organisational forms, as individual and organisational actors not only perform their own role, but also "take the role of the other" when the other is weak or under-performing (Etzkowitz et al., 2003). Through this creative process, relationships among the institutional spheres of university, industry and government are continuously reshaped to enhance innovation (Etzkowitz and Leydesdorff, 1998) bringing forth new technologies, new firms and new types of relationships in a sustained systemic effort. 
DOI: $10.21522 /$ TIJAR.2014.04.02.Art022

ISSN: $2520-3088$

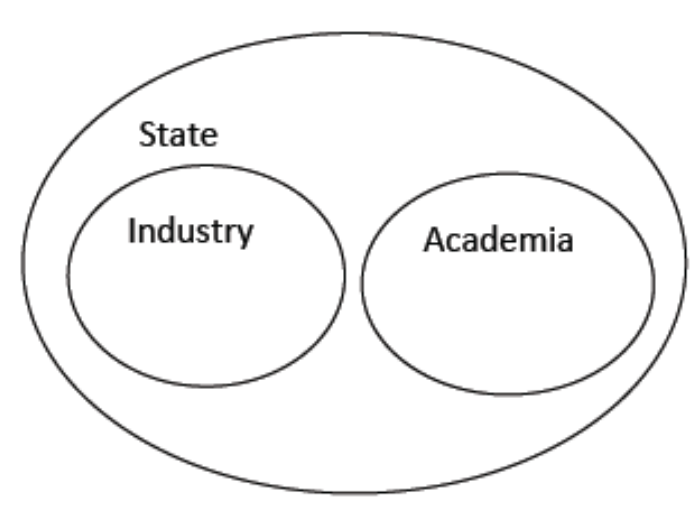

Statist model
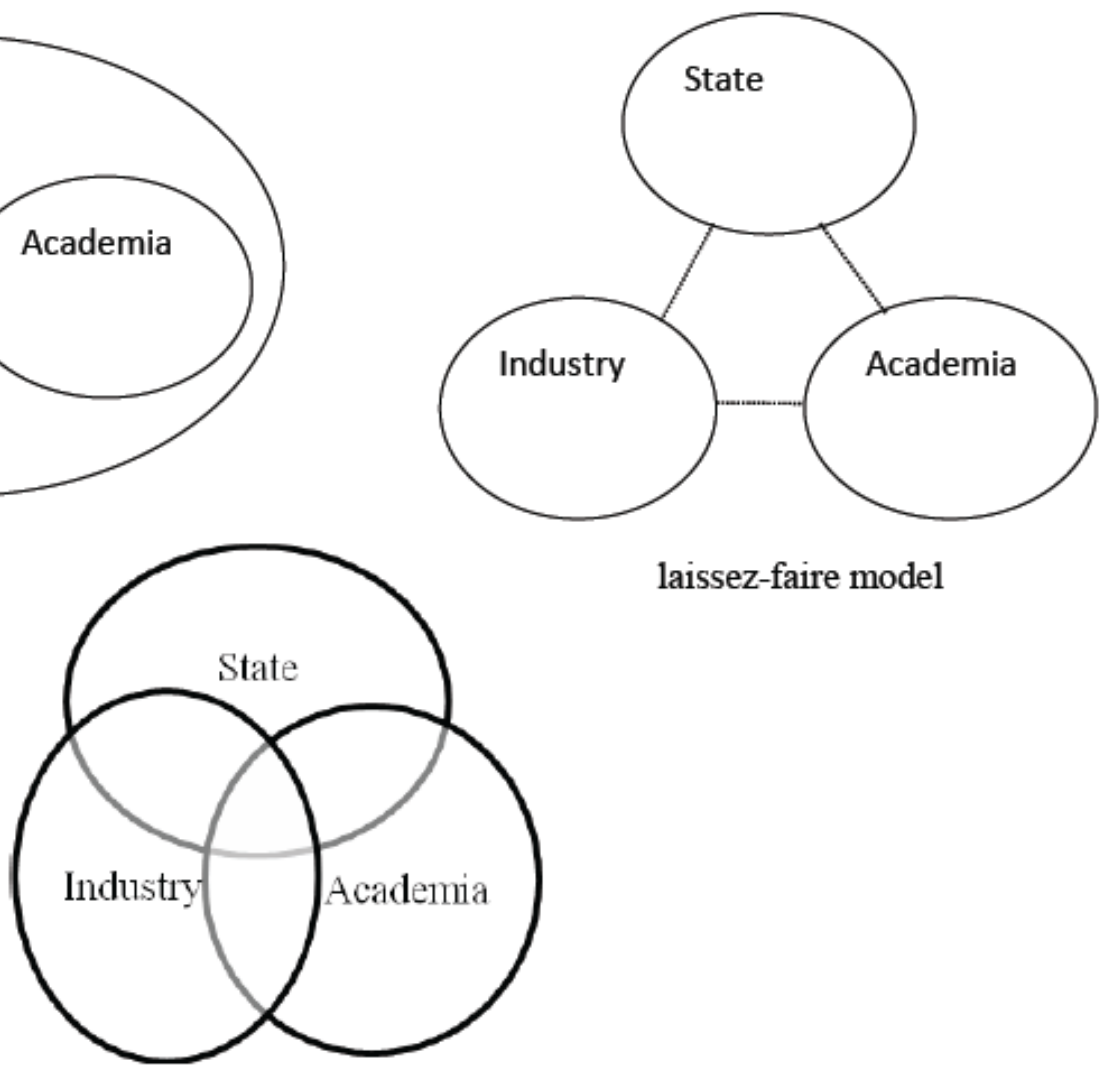

laissez-faire model

A balance Triple Helix model

Figure 1. Triple helix systems

Source: Etzkowitz, H. and leydesdorff, 2000

A (neo) evolutionary perspective (Luhmann, 1984) inspired by the theory of social systems of communication and mathematical theory of communication (Shannon, 1948), that views the University, Industry and Government as co-evolving subsets of social systems. The interaction between them occurs through an overlay of recursive networks and organizations which reshape their institutional arrangements through reflexive sub-dynamics (such as markets and technological innovations) (Leydesdorff et al., 2009). Such forms of interaction are part of two processes of communication and differentiation between science and markets, and between private and public control at the level of universities, industries and government that allow various degrees of selective mutual adjustment (Etzkowitz et al., 1998). Furthermore, internal differentiation within each institutional sphere generates new types of links and structures between them creating new network integration mechanisms (Etzkowitz et al., 1998).

The institutional spheres are also seen as selection environments while the institutional communications between them act as selection mechanisms that generate new innovation environments and ensure 'regeneration' of the system (Etzkowitz et al., 1998). The activities of the Triple Helix actors are measured in terms of probabilistic entropy which when negative suggests a self-organizing dynamic that may temporarily be stabilized in the overlay of communications among the carrying agencies (Etzkowitz et al., 1998). This dynamism systemic nature of the Triple Helix interactions is an underlying dimension of both perspectives originating from their common vision of Triple Helix interactions as manifestations of social systems (Luhmann et al., 1984). However, an explicit analytical framework for conceptualizing Triple Helix systems has not been provided so far.

\section{Conceptual framework}

The conceptual framework for the present study shows the relationship between independent variables and the dependent variable. Independent variables include broadband diffusion, broadband collaboration, electronic research and online broadband products while technological innovation is the 
dependent variable. Technological innovations are the effect of new online products usability, broadband processes, and broadband services that may arise as a result of widespread broadband application. Broadband diffusion influences all the other independent variables namely, broadband collaboration, electronic research and online broadband products which is depicted in the framework with a link. Broadband collaborations, online products usability and electronic research (e-research) are the processes, products and services that arise from dynamic interactions and network formations between academia, industry and government through broadband diffusion. This is because this study adopts a system dynamic structure. Broadband policy is taken as the moderating variable in the model. Policy implication on broadband influences the direction and vigour in technological innovativeness of organizations within Kenya.

Independent Variables

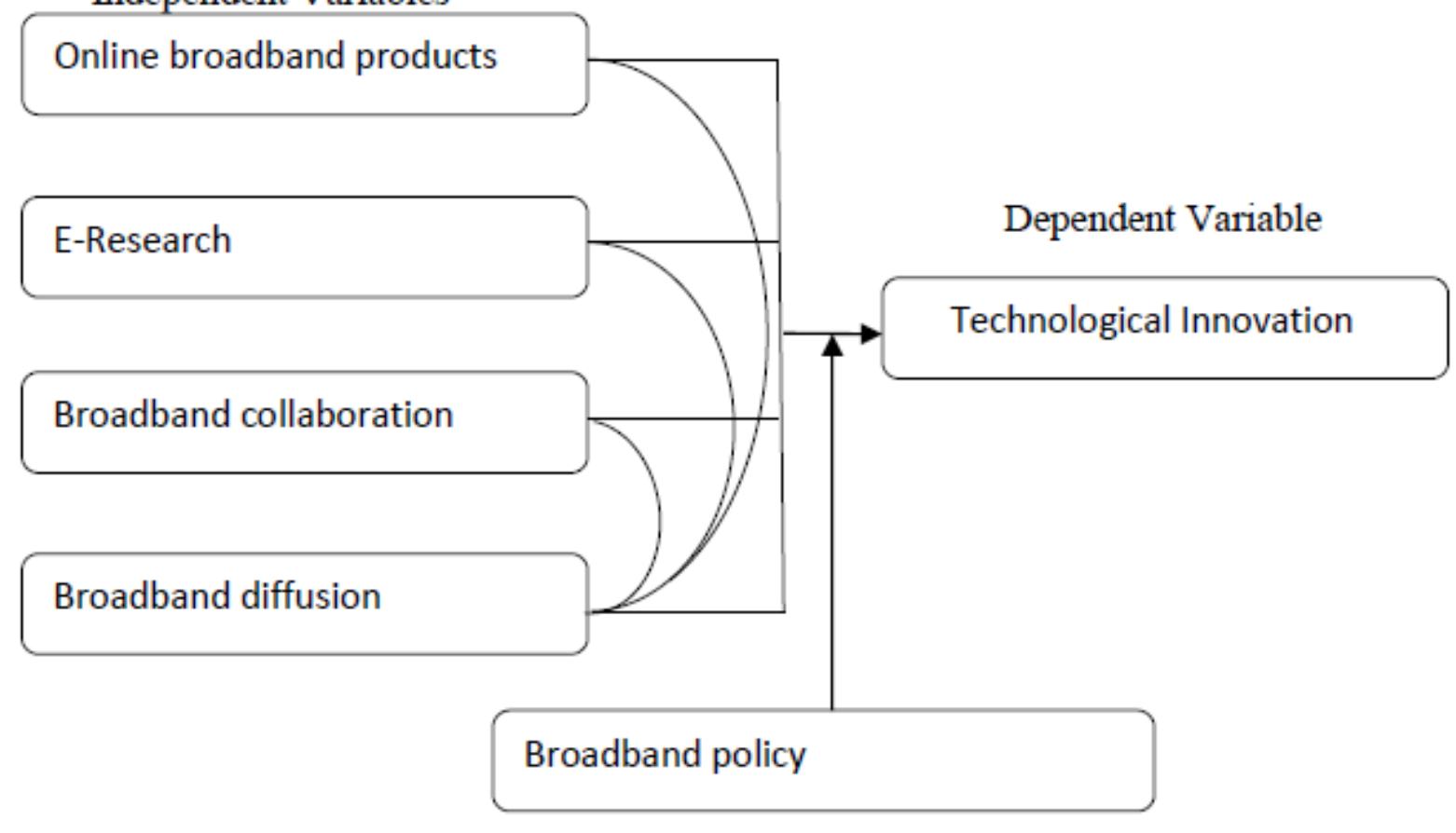

Moderating Variable

Figure 2. Conceptual framework

\section{Methods}

\section{Empirical model}

The study uses a logistic regression model as an inferential analysis tool in the quantitative aspects of the research. In the research, IHL were viewed as adopters of broadband innovations. Once broadband innovations were adopted, consumers of broadband innovations (i.e., students, academic staff and administrative staff) intend to be satisfied by the systems adopted and implemented. This assumption is guided by utility maximization theory, and taking the rational choice theory, universities would expect to realize most of the outputs envisaged in each adoption. Consumers therefore, would get satisfaction if the innovations were effectively implemented $\mathrm{U}\left(a_{i}\right)$. If there was failure in effective implementation then utility would be $\mathrm{U}\left(a_{j}\right)$.

The utility maximization model therefore would be:

$$
\mathrm{U}\left(a_{i}\right)>\mathrm{U}\left(a_{j}\right)
$$

Where $\mathrm{U}\left(a_{i}\right)$ and $\mathrm{U}\left(a_{j}\right)$ denote the utility derived from the innovations' effective implementation $\mathrm{U}\left(a_{i}\right)$ and failure ineffective implementation $\mathrm{U}\left(a_{j}\right)$. The output of this utility model is a binary output (effective implementation (1) and ineffective implementation (0)).The dependent variable took binary response outcomes. Assuming Y to represent successful innovation implementation, then: 
DOI: $10.21522 / \mathrm{TIJ} A R .2014 .04 .02 . A r t 022$

ISSN: $2520-3088$

$$
y_{i}=\left[\begin{array}{l}
1 \text { if an innovation was effectively implemented }- \text { probability } p \\
0 \text { if innovation implementation was not ef fective }- \text { probsbility } 1-p
\end{array}\right.
$$

These values of 1 and 0 are chosen based on the binary outcome of:

$$
P_{i} \equiv \operatorname{Pr}\left[y_{i}=1 \mid X\right]=F\left(x_{i}^{\prime} \beta\right)
$$

Where $F($.) is a specific function. In order to ensure that $0 \leq p \leq 1$, then it is natural to specify $F($.) to be a cumulative distribution function. The estimation model selected as appropriate for this research study was the logit model. According to (Peng, Lee, \& Ingersoll, 2002), Logit models are models that can be used to analyze and predict data whose outcome is categorical. Logistic regression analysis is thus suitable where there is a dichotomous outcome - of success or failure. Furthermore, a logit model is well suited for describing and testing relationships of categorical outcomes and one or more categorical or continuous predictors where errors are neither normally distributed nor constant across the entire data range.

Logistic regression is based on the logit concept, which is a natural logarithm of odds ratio. Peng, et al., (2002) defined the logistic model as shown below:

$$
\log (\mathrm{Y})=\ln (\text { odds })-\frac{\ln (\pi)}{1-\pi}=\alpha+\beta X+\varepsilon
$$

Where

$\alpha$ is $\mathrm{Y}$ intercept.

$\beta$ is a vector of the regression coefficient.

$\pi$ is the probability of the outcome of interest i.e., innovation effectiveness.

$\mathrm{e}=2.71828$ which is the base of natural log.

Taking the inverse therefore:

$\pi_{i}=\operatorname{Pr}\left(Y_{i}=\right.$ outcome of innovation $\left.\mid X_{i}=x_{i}\right)=\frac{\exp \left(\beta 0+\beta 1 x_{i}\right)}{1+\exp \left(\beta 0+\beta 1 x_{i}\right)}$

Where

$\mathrm{X}$ is a vector of categorical or continuous variables.

$\mathrm{Y}$ is always a categorical (dichotomous) variable.

The value of $\beta$ determines the relationship between $X$ and $Y$. If $\beta>0$, larger or smaller values of $X$ are associated with larger or smaller values of the logit of $\mathrm{Y}$. The converse also applies: if $\beta<0$, larger or smaller values of $\mathrm{X}$ are associated with larger or smaller value of the logit of $\mathrm{Y}$. And where $\beta$ $=0$ there is no linear relationship.

For a multiple predictor mode (Peng, et al., 2002)

$$
\operatorname{logit}(Y)=\frac{\ln (\pi)}{1-\pi}=\alpha+\beta_{1} X_{1}+\ldots \ldots+\beta_{n} X_{n}
$$

Therefore

$$
\pi=\operatorname{Pr}\left(Y=\text { outcome } \mid X_{1}=X_{2}=X_{3}\right)=\frac{\exp \left(\alpha+\beta_{1} x_{1}+\cdots+\beta_{n} x_{n}\right)}{1+\exp \left(\beta_{1} x_{1}+\cdots+\beta_{n} x_{n}\right)}
$$

Where

$\pi=$ probability of an outcome of technological innovation implementation. $\alpha=\mathrm{Y}$ intercept term.

$\beta=$ regression coefficients.

$\mathrm{Xs}=$ set of predictors.

$\alpha$ and $\beta$ were estimated using the Markov chain Monte Carlo (MC) method for maximum likelihood. Interpretation of results was done using odds ratio for both categorical and continuous predictors. The compound predictors were: Online broadband products (X1); e-Research (X2); Broadband diffusion (X3); Broadband collaboration(X4) and Broadband policy(X5) - against an independent variable: Innovation $(\mathrm{Y})$. As noted, independent variables (X1....X5) were composite variables and therefore factor analysis was used to combine the sub-variables to one composite variable to fit into the model. A three-predictor logistic model was used to fit the data for testing. The relationship between the likelihood of a broadband innovation's effective implementation ( $\mathrm{Y}$ ) and its determinants (X1...X5) is described using the following equation: 
$Y=\alpha+\beta_{1} X_{1}+\ldots \ldots+\beta_{5} X_{5}+\varepsilon_{i}$

The logistic regression model is given as follows:

$\ln \left(\frac{P}{1-P}\right)=\alpha+\beta_{1} X_{1}+\ldots+\beta_{5} X_{5}+\varepsilon_{5}$

Where

$\mathrm{P}$ probability that a broadband innovation was effectively implemented; 1-P probability that a broadband innovation was not effectively implemented;

In natural logarithms;

$\alpha$ Constant of the equation;

$\beta_{1} \ldots \beta_{5}$ : The parameters to be estimated

$X_{1} \ldots X_{5}$ :The explanatory variables;

$X_{1}$ : Online broadband products;

$X_{2}$ : e-Research;

$X_{3}$ : Broadband diffusion

$X_{4}$ : Broadband collaboration

$X_{5}$ : Broadband policy

and

$\varepsilon_{i}$ : The error term.

\section{Definition of measurement variables}

Technological Innovation(Y): This is the dependent variable. It was measured on the basis of whether a technological innovation was effectively implemented or not. In order to be effectively implemented meant that the innovation was in use and had achieved $60 \%$ of other objectives. A value of 1 meant effectiveness in implementation while 0 indicated not effectively implemented.

Online broadband products $\left(X_{1}\right.$.): This independent variable measured the impact broadband diffusion played in implementation of online broadband technological innovation products. This was measured by assessing users and stakeholder's perceptions of the products effectiveness in running the day-to-day activities in IHL

E-research $\left(X_{2}\right)$ : This independent variable measured the impact broadband diffusion played in implementation of electronic research in IHL. It is an innovation metric that measured the levels of conducting research effectively from a user's point of view by utilizing broadband technologies. A stakeholder view was necessary to ascertain the degree at which e-research innovation was implemented.

Broadband diffusion $\left(X_{3}\right)$ : This independent variable influenced all the other independent variables. It had an impact on broadband products, e-research and collaboration. The factors in this variable construct that the research focused on are: broadband price; bandwidth availability, broadband accessibility; broadband usability and broadband speed. The research seek opinion on their influence on broadband diffusion within IHL

Broadband collaboration $\left(X_{4}\right)$ : This independent variable measured the impact broadband diffusion played in implementation of collaborative engagements of IHL and other organizations and institutions. It measured impact of collaborative network formations and was obtained from stakeholder perceptions in realization of their expectations and benefits from these interactions.

Broadband Policy $\left(X_{5}\right)$ : This is a moderating variable and it influenced all the other variables. Policy on broadband determined the capacity of innovation, the direction and vigour of innovation implementation.

\section{Measurement development}

The items used for measurement in this research were either developed based on the literature review, adapted from previously validated measures or derived through consultation with ICT experts to ensure that they are valid and reliable. A five-point Likert scale arranged in order of magnitude was employed to assess responses. 
DOI: $10.21522 /$ TIJAR.2014.04.02.Art022

ISSN: $2520-3088$

A representative sample was randomly chosen and used to conduct a pilot test of the measures. Partial least-squares (PLS) analysis technique was applied to test the measurement model to determine the internal consistency reliability and construct validity of the study variables. The technique was also used to test strength and direction of the relationships between variables used in the model (Lohmoller, 1989 and Fronell, 1982). There are only 39 universities in Kenya which represents a small sample population. Therefore PLS was preferred for the research. PLS is applicable for testing and estimating small sample sizes as it converges quickly even for large models with many variables and constructs (Lohmoller, 1989).

Table 1. Summary of measurement scales

\begin{tabular}{|c|c|c|}
\hline Variable construct & Measurement & \\
\hline \multirow[t]{7}{*}{$\begin{array}{l}\text { 1. Online Broadband } \\
\text { Products }\end{array}$} & Code & Measure \\
\hline & DLibrary & $\begin{array}{l}\text { Indicate the popularity of digital library in } \\
\text { your institution }\end{array}$ \\
\hline & eLearn & $\begin{array}{l}\text { Indicate the level of popularity of the e- } \\
\text { learning program in your institution }\end{array}$ \\
\hline & LMS & $\begin{array}{l}\text { The Learning Management System(LMS) is } \\
\text { very effective in my institution }\end{array}$ \\
\hline & ARMS & $\begin{array}{l}\text { The academics record management system is } \\
\text { used effectively by all faculty in my } \\
\text { institution }\end{array}$ \\
\hline & Portal & $\begin{array}{l}\text { ALL students in my institution access and use } \\
\text { their portal effectively }\end{array}$ \\
\hline & onAdm & $\begin{array}{l}\text { Online admission is effectively used for } \\
\text { admission purposes }\end{array}$ \\
\hline \multirow[t]{6}{*}{ 2. e-Research } & onLiJournals & $\begin{array}{l}\text { Online journal repository is easily accessible } \\
\text { in my institution }\end{array}$ \\
\hline & Conferences & $\begin{array}{l}\text { International conference, workshop or } \\
\text { symposia are common in my institution }\end{array}$ \\
\hline & onLiJourn & $\begin{array}{l}\text { Indicate the level of popularity of online } \\
\text { journals in your institution }\end{array}$ \\
\hline & Incubators1 & $\begin{array}{l}\text { Technology incubator(s) or accelerator(s) are } \\
\text { popular in my institution }\end{array}$ \\
\hline & Incubators2 & $\begin{array}{l}\text { Technology incubator(s) or accelerator(s) in } \\
\text { my institution have produced many useful } \\
\text { technological applications }\end{array}$ \\
\hline & Incubators3 & $\begin{array}{l}\text { Many members of my institution have } \\
\text { benefited from these incubator(s) or } \\
\text { accelerator(s) }\end{array}$ \\
\hline \multirow[t]{5}{*}{$\begin{array}{l}\text { 3. Broadband } \\
\text { collaborations }\end{array}$} & Collab1 & $\begin{array}{l}\text { My institution collaborates with many } \\
\text { institutions and organizations }\end{array}$ \\
\hline & Collab2 & $\begin{array}{l}\text { Many members of my institution have } \\
\text { benefited from these collaborations }\end{array}$ \\
\hline & Collab3 & $\begin{array}{l}\text { My institution has benefited immensely from } \\
\text { the collaborations }\end{array}$ \\
\hline & Collab4 & $\begin{array}{l}\text { Most of the collaborations are broadband } \\
\text { based }\end{array}$ \\
\hline & Collab5 & $\begin{array}{l}\text { There are many completed and ongoing } \\
\text { broadband based projects undertaken jointly } \\
\text { with other organizations in my institution }\end{array}$ \\
\hline
\end{tabular}




\begin{tabular}{|c|c|c|}
\hline & Collab6 & $\begin{array}{l}\text { Broadband based projects undertaken jointly } \\
\text { with other organizations have resulted in } \\
\text { many innovative products/applications }\end{array}$ \\
\hline \multirow[t]{6}{*}{ 4. Broadband diffusion } & BBdiffusion1 & $\begin{array}{l}\text { Internet connection speed in my institution is } \\
\text { very good }\end{array}$ \\
\hline & BBdiffusion2 & $\begin{array}{l}\text { There are many internet users in my } \\
\text { institution }\end{array}$ \\
\hline & BBdiffusion3 & The high cost of bandwidth limits its usability \\
\hline & BBdiffusion4 & $\begin{array}{l}\text { Amount of bandwidth available in my } \\
\text { institution is adequate }\end{array}$ \\
\hline & BBdiffusion5 & $\begin{array}{l}\text { I can access the internet from within my } \\
\text { institution }\end{array}$ \\
\hline & BBdiffusion6 & $\begin{array}{l}\text { I can use broadband comfortably to perform } \\
\text { my academic work }\end{array}$ \\
\hline \multirow[t]{6}{*}{$\begin{array}{l}\text { 5. Influence of } \\
\text { Broadband policies }\end{array}$} & BBP1 & $\begin{array}{l}\text { Adequate training is provided on the use of } \\
\text { digital library and other ICT-based academic } \\
\text { management tools in my institution }\end{array}$ \\
\hline & $\mathrm{BBP} 2$ & $\begin{array}{l}\text { My institution procures adequate bandwidth } \\
\text { to sustain broadband requirements }\end{array}$ \\
\hline & BBP3 & $\begin{array}{l}\text { My institution encourages the use of online } \\
\text { tools in admission and students' records } \\
\text { management }\end{array}$ \\
\hline & BBP4 & $\begin{array}{l}\text { My institution has implemented a distant } \\
\text { online learning or e-learning program that is } \\
\text { very popular }\end{array}$ \\
\hline & BBP5 & $\begin{array}{l}\text { Broadband collaborations and linkages with } \\
\text { other organizations are common in my } \\
\text { institution }\end{array}$ \\
\hline & BBP6 & $\begin{array}{l}\text { My institution encourages broadband } \\
\text { collaborative research }\end{array}$ \\
\hline \multirow[t]{4}{*}{$\begin{array}{l}\text { 6. Broadband on } \\
\text { Innovations }\end{array}$} & BBD-INN1 & $\begin{array}{l}\text { Broadband diffusion influences online } \\
\text { product innovation in my institution }\end{array}$ \\
\hline & BBD-INN2 & $\begin{array}{l}\text { Broadband diffusion impacts positively on } \\
\text { collaboration in my institution }\end{array}$ \\
\hline & BBD-INN3 & $\begin{array}{l}\text { Broadband diffusion has an influence on e- } \\
\text { research in my institution }\end{array}$ \\
\hline & BBD-INN4 & $\begin{array}{l}\text { Broadband policy has an impact on } \\
\text { innovation in my institution }\end{array}$ \\
\hline
\end{tabular}

\section{Results}

\section{Validation of the measurement scale}

In order to assess the reliability and validity of the measures before using them in the research model, the study applied a two-step approach as suggested by Anderson and Gerbing (1988). Analysis of the measurement model was conducted first before testing the structural relationships between latent constructs.

$$
\begin{aligned}
& \text { Composite Reliability }=\sum_{\mathrm{i}=1}^{\mathrm{n}} \mathrm{x}_{\mathrm{i}}{ }^{2} /\left(\sum_{\mathrm{i}=1}^{\mathrm{n}} \mathrm{x}_{\mathrm{i}}{ }^{2}+\left(\sum_{\mathrm{i}=1}^{\mathrm{n}} \mathrm{y}_{\mathrm{i}}\right)\right) \\
& \text { Average Variance Extracted }=\left(\sum_{\mathrm{i}=1}^{\mathrm{n}} \mathrm{x}_{\mathrm{i}}^{2}\right) / \mathrm{n}
\end{aligned}
$$


DOI: $10.21522 /$ TIJAR.2014.04.02.Art022

ISSN: $2520-3088$

Where $\mathrm{x}$ is the factor loading, $\mathrm{y}$ is error variance and $\mathrm{n}$ is the number of indicators in each variable construct

Table 2. Psychometric properties of the constructs

\begin{tabular}{|c|c|c|c|c|c|c|}
\hline Construct & $\begin{array}{l}\text { Measurement } \\
\text { Code }\end{array}$ & Loading & $\begin{array}{l}\text { t- } \\
\text { value }\end{array}$ & $\begin{array}{l}\text { Composite } \\
\text { reliability }\end{array}$ & $\begin{array}{l}\text { Cronbach's } \\
\text { alpha }(\alpha)\end{array}$ & $\begin{array}{l}\text { Average } \\
\text { Variance } \\
\text { (AV) }\end{array}$ \\
\hline $\begin{array}{l}\text { 1. Online } \\
\text { broadband } \\
\text { products }\end{array}$ & $\begin{array}{l}\text { DLibrary } \\
\text { eLearn } \\
\text { LMS } \\
\text { ARMS } \\
\text { Portal } \\
\text { onAdm }\end{array}$ & $\begin{array}{l}.887 \\
.910 \\
.812 \\
.844 \\
.815 \\
.840\end{array}$ & $\begin{array}{l}29.048 \\
20.324 \\
27.879 \\
33.642 \\
39.634 \\
26.948\end{array}$ & 0.897 & 0.740 & 0.726 \\
\hline 2. e-Research & $\begin{array}{l}\text { onLiJournals } \\
\text { Conferences } \\
\text { onLiJourn } \\
\text { Incubators1 } \\
\text { Incubators2 } \\
\text { Incubators3 }\end{array}$ & $\begin{array}{l}.820 \\
.650 \\
.678 \\
.595 \\
.788 \\
.701\end{array}$ & $\begin{array}{l}24.870 \\
28.187 \\
22.944 \\
43.465 \\
38.447 \\
43.958\end{array}$ & 0.860 & 0.784 & 0,503 \\
\hline $\begin{array}{l}\text { 3. Broadband } \\
\text { Collaborations }\end{array}$ & $\begin{array}{l}\text { Collab1 } \\
\text { Collab2 } \\
\text { Collab3 } \\
\text { Collab4 } \\
\text { Collab5 } \\
\text { Collab6 }\end{array}$ & $\begin{array}{l}.887 \\
.910 \\
.812 \\
.844 \\
.581 \\
.840\end{array}$ & $\begin{array}{l}29.048 \\
20.324 \\
27.879 \\
33.642 \\
32.870 \\
26.948\end{array}$ & 0.549 & 0.726 & 0.671 \\
\hline $\begin{array}{l}\text { 4. Broadband } \\
\text { Diffusion }\end{array}$ & $\begin{array}{l}\text { BBdiffusion1 } \\
\text { BBdiffusion2 } \\
\text { BBdiffusion3 } \\
\text { BBdiffusion4 } \\
\text { BBdiffusion5 } \\
\text { BBdiffusion6 }\end{array}$ & $\begin{array}{l}.751 \\
.767 \\
.652 \\
.735 \\
.768 \\
.765\end{array}$ & $\begin{array}{l}27.035 \\
22.421 \\
21.055 \\
31.202 \\
38.935 \\
31.622\end{array}$ & 0.883 & 0.741 & 0.548 \\
\hline $\begin{array}{l}\text { 5. Broadband } \\
\text { policies }\end{array}$ & $\begin{array}{l}\text { BBP1 } \\
\text { BBP2 } \\
\text { BBP3 } \\
\text { BBP4 } \\
\text { BBP5 } \\
\text { BBP6 }\end{array}$ & $\begin{array}{l}.630 \\
.543 \\
.834 \\
.769 \\
.635 \\
.755\end{array}$ & $\begin{array}{l}22.602 \\
25.974 \\
27.271 \\
25.647 \\
23.068 \\
26.513\end{array}$ & 0.875 & 0.876 & 0.492 \\
\hline
\end{tabular}

Table 2 shows reliability measures above the recommended level of 0.70 as an indicator for adequate internal consistency(Hair, Anderson, Tatham and Black, 1995).convergent validity is adequate when constructs have an average variance extracted (AVE) of at least 0.5(Fronell, 1982) or when items loading on their associated factors are above 0.5(Hair, Anderson, Tatham and Black, 1995). Furthermore AVE from the construct should be greater than the variance shared between a particular construct and other constructs in the model (Chin, 1998). Therefore, the constructs used in this study illustrated satisfactory convergent and discriminate validity.

\section{Overall regression model}

In order to develop a model to assess technological innovation, a logistic regression model was constructed using Innovative as the dependent variable while broadband diffusion (BBdifussion), e- 
Research (eResearch), broadband Collaboration (COLLAB) and online broadband products (OnLineProd) as covariates or independent variables.

\section{Overall regression model analysis}

The underlying section provides inferential statistical results and their interpretation as provided in the Logistic regression model adopted in this study for analysis. Peng et al. (2002) guidelines provided the basis for analysis. Peng et al. (2002) claimed that to test the soundness of a logistic regression model, the following tests were important considerations: overall model evaluation; goodness-of-fit statistics; statistical tests of individual predictors and validations of predicted probabilities.

The Omnibus Tests of Model Coefficients is used to check that the new model (with explanatory variables included) is an improvement over the baseline model. The test uses chi-square tests to see if there is a significant difference between the Log-likelihoods (specifically the -2LLs) of the baseline model and the model created. If the new model created has a significantly reduced -2LL compared to the baseline, then it suggests that the new model is explaining more of the variance in the outcome and is an improvement! The $\mathrm{R}^{2}$ values tell us approximately how much variation in the outcome is explained by the new created model.

Before the data was subjected to logistic regression analysis, it was necessary to run multicorrelation, validity and reliability tests to determine the constructs necessary for the model. These tests were done earlier and explanations were provided. The following table shows results for the logistic regression model estimation.

Table 3. Statistics for the overall regression model analysis

\begin{tabular}{lllll}
\hline & B & S.E & Wald & Sig. (2-tailed) \\
\hline OnLineProd & 4.081 & 1.346 & 7.582 & .002 \\
eResearch & -.377 & .281 & 6.799 & .181 \\
BBdifussion & -.338 & .280 & 8.372 & .227 \\
COLLAB & -3.119 & 1.308 & 6.297 & .017 \\
BBPtotal & .121 & .249 & 8.146 & .625 \\
\hline
\end{tabular}

The Hosmer and Lemeshow Test Chi-square of 46.405 with a p-value of 0.000 indicated that the model as a whole fitted significantly better than a null model (an empty model without a predictor). With a log likelihood of 37.804 showed that the model fitted the data. Looking at the data, the chisquared statistic on which it is based is very dependent on sample size so the value cannot be interpreted in isolation from the size of the sample. As it happens, this pvalue may change when we allow for interactions in our data. Exp (B) stands for confidence interval and this option requests the range of values that we are confident that each odds ratio lies within. The setting of $95 \%$ means that there is only a $p<.05$ that the value for the odds ratio, $\exp (\mathrm{B})$, lies outside the calculated range.

Another descriptive measure of goodness of fit is $R^{2}$. Peng et al. (2002) explained that in a linear regression, $R^{2}$ is the proportion of the variations in the dependent variable that could be explained by predictor variables. However, in logistic regression, $R^{2}$ is not well defined and in this study it was supplemented by the Cox and Snell $R^{2}$ and the Nagelkerke $R^{2}$. The results of the model showed that Cox and Snell $R^{2}$ was 0.667 while the Nagelkerke $R^{2}$ was 0.900 . This meant the predictor variables explained between $66.7 \%$ and $90.0 \%$ of the changes in innovation implementation effectiveness as per the data collected in this study.

Table 4. Inferential statistics for the overall regression model

\begin{tabular}{ll}
\hline Statistic & Value \\
\hline Hosmer and Lemeshow TestChi- & 46.405 \\
square & \\
p-value & 0.000 \\
Log likelihood & 37.804 \\
Cox \& Snell R Square & 0.667 \\
Nagelkerke R Square & 0.900 \\
\hline
\end{tabular}




\begin{tabular}{ll}
\hline Omnibus Tests Chi-square & 164.883 \\
Sig. & 0.000
\end{tabular}

The inferential goodness-of-fit test is the Omnibus tests of model coefficient test, which yielded chi square of 164.883 and a $\mathrm{p}$-value of $0.000(\mathrm{p}<0.005)$. The null hypothesis could have stated that the data fits the logistic regression model, with the alternative stating that the data does not fit the logistic regression model. A p-value of 0.000 means that the null hypothesis was rejected. It shows that there was evidence for goodness of fit of the data. This findings supported Peng et al., 2002 and Dwivedi et al., 2010 studies.

In this section the model always guesses 'no' because variable constructs were not innovative and therefore the approach to prediction was correct $59.3 \%$ of the time. After regression the model correctly classified the outcome for $98.7 \%$ of the cases compared to $59.3 \%$ in the null model. This was a great improvement. Below is the graph showing the outcome classification and the predicted probabilities.

\section{Discussion}

Overall, the findings of the study revealed that institutions of higher learning in Kenya are not technologically innovative and have a low level of broadband adoption. These findings were supported by the frequencies of the responses from the respondents which were presented in the form of percentages. All the four factors that were used to assess technological innovation presented a low level of influence on technological innovation assessment. Furthermore, broadband policy had little impact on technological innovations assessments in these institutions.

\section{Conclusion}

Based on the findings of the research, it can be concluded that institutions of higher learning in Kenya have a positive but low capacity in technological innovation. The adoption of broadband by this institutions has the potential to improve technological innovations. Although this institutions have continued to perform well in terms of student enrolments, this could have been made better by adopting modern innovative techniques in the day to day activities of management and teaching. Adoption of distance and e-learning programs could boost further student enrolments by enhancing widespread access to education to those at a distant across east Africa or further.

The application of online admissions, student portals, and digital libraries, learning management systems, academic records management, e-research and e-collaborations could not only boost research output but also improve management of large data and information available in this institutions. Broadband diffusion is inhibited by poor infrastructural development attributed to high costs of connections and bandwidth acquisition and a high demand for broadband among the students and staff. Policies in broadband regulation from the national government and institutional governance are prudent in controlling and enabling access to this important resource for innovative purpose.

\section{Areas for further research}

This study adopted system dynamic modelling using swarm technology to assess technological innovation for a country as a whole or a particular sector. Dynamics system modelling involve broadband interaction and network formation between government, academia and industry. Studying the networks involving government, academia and industry together is very wide. Due to limitations and time constraints, this study was only able to study network formations only in academia. Further research therefore is recommended to study network formations in the other two sectors namely government and industry. This will complete the model of system dynamism for the whole country, Kenya. 


\section{References}

[1]. Anderson, J.C., Gerbing, D.W., (1988). Structural equation modeling in practice: a review and recommended two-step approach. Psychological Bulletin 103, 423-441.

[2]. Bertrand, W. E. (2010). Higher education and technology transfer: The effects of "Technosclerosis" on development. Journal of International Affairs, 64(1), 101-120.

[3]. Dodds, T. (2007). Information technology, a contribution to innovation in higher education. Available online: http://www.mendeley.com/research/informationtechnology-contributor-innovation-higher-education.

[4]. Dong, L., Neufeld, D., \& Higgins, C. (2008).Testing Klein and Sorra's innovation implementation model: An empirical examination. Journal of Engineering and Technology, 25, 237-255.

[5]. Etzkowitz, H., Leydesdorff, L. 1998.The endless transition: A "triple helix" of universityindustrygovernment relations. Minerva 36, 203-208.

[6]. Etzkowitz, H. 2003. Innovation in Innovation: The Triple Helix of University-Industry- Government Relations. Social Science Information 42, 293-338.

[7]. Etzkowitz, H. 2008. The Triple Helix: University-Industry-Government Innovation in Action. Routledge, London.

[8]. Etzkowitz, H. 2012. Triple Helix Clusters: Boundary Permeability at University-Industry Government Interfaces as a Regional Innovation Strategy. Environment \& Planning C: Government and Policy. In Press

[9]. Etzkowitz, H., Leydesdorff, L. 2000. The dynamics of innovation: from National Systems and "Mode 2" to a Triple Helix of university-industry-government relations. Research Policy 29, 109-123.

[10]. Gibbons, M., Limoges, C., Nowotny H., Schwartzmann, S., Scott, P. and Trow, M. 1994. The New Production of Knowledge, Sage.

[11]. Godin and Gingras, 2000. The place of universities in the system of knowledge production. Research Policy 29, 273-278.

[12]. Hair, J.F., Anderson, R.E., Tatham, R.L., Black, W.C., (1995). Multivariate Data Analysis with Readings. Prentice-Hall International, Englewood Cliffs.

[13]. http://ehlt.flinders.edu.au/ education/iej/articles/v6n4/jhurree/paper.pdf.

[14]. http://ssrn.com/abstract=2168595orhttp://dx.doi.org/10.2139/ssrn.2168595,

http://www.ascilite2012.org/images/custom/mirriahi,_negin_-_identifying_key.pdf.

[15]. Jaffer, S., Ng'ambi, D., \& Czerniewicz, L. (2007). The role of ICTs in higher education in South Africa:

One strategy for addressing teaching and learning challenges. International Journal of Education and Development using Information and Communication Technology (IJEDICT), 3(4), 131-142.

[16]. Jhurree, V. (2005). Technology integration in education in developing countries: Guidelines to policy makers 1. International Education Journal, 6(4), 467-483.

[17]. Leydesdorff, L. 2009. Configurational Information as Potentially Negative Entropy: The Triple Helix Model. Entropy 10, 391-410.

[18]. Lohmoller, J.B., (1989). Latent Variable Path Modeling with Partial Least Square Analysis. PhysicaVerlag, Heidelberg.

[19]. Luhmann, N., 1984. Soziale Systeme. Grundriß einer allgemeinen Theorie. Suhrkamp, Frankfurt a. M. Social Systems. Stanford Univ. Press, Stanford, 1995.

[20]. McGregor, J. H. (2002). Flexible scheduling: How does a principal facilitate implementation? School Libraries Worldwide, 8(1), 71-84, available online on http://www.ala.org/aasl/aaslpubsandjournals/slmrb/slmrcontents/volume9/flexible\#findings.

[21]. Mirriahi, N., Dawson, S., \& Hoven, D. (2012). Identifying key actors for technology adoption in higher education: A social network approach. Acsilite 2012 future challenges, sustainable futures. Retrieved from:

[22]. Oliver, R. (2002). The role of ICT in higher education for the 21st century: ICT as a change agent for education. Proceedings of the Higher Education for the 21st Century Conference. Miri, Sarawak: Curtin University.

[23]. Peng, C.-Y. J., Lee, K. L., \& Ingersoll, G. M. (2002). An introduction to logistic regression analysis and reporting. The Journal of Educational Research, 96(1), 3- 14.doi:10.1080/00220670209598786.

[24]. Sawang, S. \& Unsworth, K. (2011). A model of organizational innovation implementation effectiveness in small to medium firms. International Journal of Innovation Management, 15 (5), 1-22. Available online.

[25]. Schumpeter, J.A. 1942. Capitalism, Socialism and Democracy. George Allen \& Unwin, New York. 
DOI: $10.21522 / \mathrm{TIJAR} .2014 .04 .02 . A r t 022$

ISSN: $2520-3088$

[26]. Shannon, C. E. 1948. A mathematical theory of communication. Bell System Technical Journal 27, 379423 and 623-656, July and October 1948.

[27]. Slaughter, S., L. Leslie. 1997. Academic Capitalism: Politics, Policies and the Entrepreneurial Universities. Johns Hopkins University Press, Baltimore. 